\title{
MEKANISME PENCAIRAN KREDIT USAHA RAKYAT PADA PT. BANK RAKYAT INDONESIA UNIT LUBUK BUAYA
}

\author{
Agung Orlando, Romi Susanto
}

Akademi Keuangan dan Perbankan Padang

romisusanto@akbpstie.ac.id

\begin{abstract}
People's Business Credit is financing of working capital and or investment to Micro Small Medium Enterprises in the field of productive and feasible yet not bankable business with credit limit up to Rp. 500,000,000, - partly guaranteed by the Guarantor Company. The source of funds for the distribution of people's business credit is $100 \%$ (one hundred percent) sourced from the executing bank funds collected from public funds (savings, demand deposits, and time deposits). People's Business Credit is intended to improve access to financing for micro, small and medium enterprises performing productive and viable business activities. People's business credit aims to achieve accelerated development of the real sector and empowerment of micro, small and medium enterprises in the context of poverty alleviation and expansion of employment opportunities. Mechanism in the implementation of the distribution of People's Business Credit funds at PT. Bank Rakyat Indonesia Unit Lubuk Buaya through several stages such as, credit application stage, file verification phase, credit analysis phase or examination phase, credit awarding stage, and credit disbursement stage or credit agreement.
\end{abstract}

Keywords: people's business credit,BRI

\section{PENDAHULUAN}

Pembangunan ekonomi di suatu negara sangat bergantung pada perkembangan dinamis dan kontribusi nyata dari sektor perbankan, peran perbankan dalam pembangunan ekonomi adalah mengalirkan dana bagi kegiatan ekonomi yaitu salah satunya dalam bentuk perkreditan bagi masyarakat perseorangan atau badan usaha.Kredit adalah penyediaan uang atau tagihan yang dapat dipersamakan dengan itu, Kredit mempunyai suatukedudukan yang strategis dimana sebagai salah satu sumber uang yang diperlukan dalam membiayai kegiatan usaha yang dapat dititikberatkansebagai salah satu kunci kehidupan bagi setiap manusia,kredit memiliki unsur kesepakatan, kepercayan dan jangka waktu.

Usaha mikro, kecil dan menengah juga memegang peran penting dalampembangunan ekonomi karena tingkat penyerapan tenaga kerjanya yan relative tinggidan kebutuhan modal investasinya yang kecil. Hal ini membuat UMKM tidak rentanterhadap berbagai perubahan eksternal sehingga pengembangan pada sektor UMKMdapat menunjang diversifikasi ekonomi dan percepatan perubahan structural yang merupakan prasyarat bagi pembangunan ekonomi jangka panjang yang stabil danberkesinambungan. 
Pemerintah Republik Indonesia mengeluarkan Inpres Nomor 6 tanggal 8Juni 2007 tentang Kebijakan Percepatan Pengembangan Sektor Riil danPemberdayaan UMKM yang diikuti dengan nota kesepahaman bersama antaraDepartemen Teknis, Perbankan, dan Perusahaan Penjaminan Kredit/Pembiayaankepada UMKM. Akhirnya pada tanggal 5 November 2007, Presiden R.I SusiloBambang Yudoyono meresmikan kredit bagi UMKM dengan pola penjaminandengan nama Kredit Usaha Rakyat (KUR) dan di dukung oleh Inpres Nomor 5 Tahun2008 tentang Fokus Program Ekonomi 2008-2009 untuk menjamin implementasi atau percepatan pelaksanaan kredit usaha rakyat ini.

Tahap awal program, Kredit Usaha Rakyat ini disediakan hanya terbatas oleh bank-bank yang ditunjuk oleh pemerintah saja,PT.Bank Rakyat Indonesia (BRI). merupakan salah satu bank yang telah ditunjuk oleh pemerintah dan dipercaya dan memenuhi syarat untuk melaksanakan kebijakan mengenai KUR dan menindaklanjuti kebijakan tersebut maka BRImengeluarkan Surat Edaran Direksi Nose: S.09c - DIR/ADK/03/2010 Atas Ketentuan Kredit Usaha Rakyat (KUR) Mikro. KUR baru dilaksanakan oleh BRI pada Maret 2008 dimana KUR ini dibagi menjadi dua, yaitu : KUR Retail dan KUR Mikro. Untuk plafond KUR Retail sebesar Rp. 500.000.000,00 (lima ratus juta rupiah), sedangkan KUR MIKRO maksimum plafond sebesar Rp. 20.000.000,00 (dua puluh juta rupiah), untuk saat ini BRI baru menyediakan KUR Mikro, hal ini karena KUR merupakan kredit yang tidak menggunakan agunan sehingga BRI tidak ingin mengambil resiko yang tinggi. Selain itu, BRI fokus terhadap UMKM.

Sejalan dengan kebijaksanaan pemerintah untuk mendorong pertumbuhan ekonomi masyarakat dengan jalan mempermudah perijinan-perijinan sebagai landasan utama berguna bagi dunia usaha serta mendorong pertumbuhan wirausaha diseluruh lapisan masyarakat Dengan pembiayaan Kredit Usaha Rakyat diharapkan dapat menanggulangi permasalahan di Indonesia dalam perekonomian yaitu kemiskinan dan pengangguran. Serta menjadikan masyarakat lebih kompetitif untuk mengembangkan usahanya sehingga akan muncul banyak kesempatan kerja.

PT. Bank Rakyat Indonesia (BRI) menjadi penyalur KUR dengan merealisasikan KUR Hingga 30 Sepember 2017, dan menjadi penyaluran tertinggi sebesar Rp52,19 triliun (74,4\% dari target), diikuti dengan Bank Mandiri sebesar Rp9,1 triliun (70,1\% dari target), dan BNI sebesar Rp5,4 triliun (45,2\% dari target). Sisanya disumbangkan oleh Bank Pembangunan Daerah (BPD) sebesar Rp5,2 Triliun (25,5\% dari target) dan Bank Umum Swasta sebesar Rp4,9 Triliun (17,8\% dari target). Oleh sebab itu bank harus bisa menetapkan mekanisme pelaksanaan kredit serta mengantisipasi masalah-masalah yang timbul, karena itu akan berpengaruh pada aktivitas perbankan itu sendiri terutama terhadap kerja operasional bank dalam penyaluran kredit untuk kesejahteraan masyarakat.

PT. Bank Rakyat Indonesia (Persero) Kantor Unit Lubuk Buaya memfokuskan pelayanan kepada masyarakat kecil dalam membantu masalah permodalan dalam upaya meningkatkan taraf hidup agar menjadi lebih baik. Fasilitas kredit yang diberikan adalah Kredit Usaha Rakyat, yang dapat digunakan untuk memenuhi kebutuhan modal usaha sehingga dapat memperlancar dan meningkatkan tingkat produksi operasional, dan juga untuk mempertahankan kelangsungan aktivitas usaha calon debitur. 
Dengan adanya Bank Rakyat Indonesia (BRI) yang memberikan Kredit Usaha Rakyat diharapkan mampu menanggulangi permasalahanpermasalahan masyarakat menengah ke bawah. Bahwasanya kredit berfungsi untuk mendorong dan melancarkan perdagangan, produksi dan jasa-jasa yang kesemuanya ditujukan untuk meningkatkan taraf hidup masyarakat. Namun tidak sedikit nasabah yang mengeluhkan ataupun tidak mampu memanfaatkan bantuan dana tersebut dengan baik. Banyak dari pelaku usaha mengakui masih belum mengerti tentang bantuan dana KUR dan tidak sedikit pula dari sekian banyak pelaku umkm kesulitan dalam mengembangkan usahanya,

Berdasarkan uraian latar belakang di atas, penulis tertarik untuk membahas lebih lanjut mengenai "Mekanisme Pencairan kredit Usaha Rakyat Pada PT. Bank Rakyat Indonesia Unit Lubuk Buaya".Berdasarkan uraian latar belakang diatas, maka rumusan masalah dalam penelitian ini adalahmaka penulis merumuskan masalah tentang bagaimana MekanismePencairan Kredit Usaha Rakyat yang dilakukan oleh PT. Bank BRI Unit Lubuk Buaya Padang?

Penelitian ini bertujuan untuk mengetahui bagaimana mekanisme pencairan kredit usaha rakyat yang ditetapkan oleh PT. Bank republik indonesia unit lubuk buaya Padang.

Adapun manfaat penelitian ini, penulis berharap dapat bermanfaat antara lain:a. Menambah Informasi dalam bidang kredit usaha rakyatdan mengetahui kebijaksanaan dari PT. Bank Rakyat Indonesia Unit Lubuk Buaya padang. b. Mengetahui bagaimanaPT. Bank Rakyat Indonesia Unit Lubuk Buaya Padangmenyalurkan kredit yang akan diberikan pada nasabah.

\section{METODE PENELITIAN}

Dalam pengumpulan data dan bahan untuk melakukan penelitian ini, penulis menggunakan metode.a. Peninjauan Langsung Ke Objek yaitu Peninjauan langsung ke objek penelitian dipilih untuk meneliti dan melakukan wawancara pihak-pikak yang berperan lansung dalam menyalurkan kredit usaha rakyat dan jawaban untuk dianalisis. Dalam penilitian ini yang menjadi objek penelitian adalah PT. Bank BRI Cabang Lubuk Buaya Padang. b. Studi Kepustakaan (Library Research) yaitu Penelitian ini dilakukan dengan cara mempelajari bukubuku, makalah-makalah, artikel-artikel, bacaan laporan-laporan dan publikasi yang berhubungan dengan objek penelitian.

\section{ANALISA DAN PEMBAHASAN}

1. Persyaratan dalam Pemberian Kredit Usaha Rakyat (KUR)

a. persyaratan Calon Debitur berupa UMKM :

1) Tidak dalam menerima pembiayaan modal kerja atau investasi dari perbankan atau tidak sedang menerima kredit program dari pemerintah, yang dibuktikan dari hasil Sistem Informasi Debitur Bank Indonesia (SID BI) pada saat permohonan kredit diajuakan Tidak sedang menerima kredit konsumtif (kredit kepemilikan rumah, kredit kendaraan bermotor, kartu kredit dan kredit konsumtif lainnya).

2) Dalam hal Usaha Mikro Kecil Menengah (UMKM) masih memiliki baki debit yang tercatat dalam SIDBI tetapi yang bersangkutan telah melunasi pinjaman, maka diperlukan surat keterangan lunas atau roya dengan 
lampiran catatan rekening Koran dari bank pemberi kredit atau pembiayaan sebelumnya.

a) Persyaratan Lembaga Keuangan Mikro

b) Telah memiliki izin usaha dari instansi yang berwenang.

c) Memiliki pengurus aktif.

d) Memiliki AD atau ART.

e) Mempunyai usaha yang layak untuk dibiayai.

f) Tidak memiliki tunggakan kredit, baik di BRI maupun di lembaga keuangan lainnya.

b. Legalitas Calon Debitur :

1) Individu : Identitas berupa KTP dan Kartu Keluarga (KK).

2) Kelompok : Surat pengukuhan dari instansi terkait atau Surat Keterangan Usaha dari Lurah atau Kepala Desa setempat dan Akte Notaris.

3) Koperasi : Anggaran dasar beserta perubahannya.

4) Badan usaha lainnya : Akte pendirian beserta perubahannya.

c. Perizinan Calon Debitur

Untuk kredit dari plafon sampai dengan Rp. 100 juta, izin usaha seperti TDP, SIUP, dan SITU dapat digantikan dengan surat keterangan izin usaha dari Lurah atau Kepala Desa setempat. Sedangkan kredit dengan plafon diatas Rp. 100 juta, calon debitur wajib memiliki izin usaha seperti TDP, SITU, dan SIUP.

2. Mekanisme Pencairan Kredit Usaha Rakyat (KUR) pada PT. Bank Rakyat Indonesia Unit Lubuk Buaya Padang

Adapun mekanisme pemberian dana Kredit Usaha Rakyat pada PT. Bank Rakyat Indonesia Unit lubuk Buaya untuk calon debitur yang ingin mengajukan, yaitu sebagai berikut:

a. Tahap Proses Pengajuan Kredit

Berdasarkan hasil penelitian pada PT. BRI Unit Lubuk Buaya Padang, maka proses pemberian KUR dilakukan secara bertahap, yaitu sebagai berikut:

1) Tahap Permohonan Kredit

Calon debitur mengajukan permohonan KUR secara tertulis kepada pihak BRI Unit Lubuk Buaya Padang. Calon debitur KUR datang ke BRI UnitUnit Lubuk Buaya Padang, kemudian ketika calon debitur datang, diterima dan dilayani oleh Customer Service KUR, calon debitur KUR mengisi formulir pendaftaran atau formulir pengajuan permohonan KUR yang sudah disediakan oleh pihak bank, kemudian ditandatangani oleh debitur.

Calon debitur KUR diharuskan memenuhi persyaratan yang telah ditetapkan dalam hal pengajuan permohonan KUR oleh pihak bank. Syarat-syarat yang perlu disertakan adalah bukti identitas diri berupa fotokopi Kartu Tanda Penduduk (KTP) yang masih berlaku, fotokopi Kartu Keluarga (KK) dan Surat Keterangan Usaha. Customer Service KUR juga memberikan informasi tentang KUR sebagai kredit yang mudah didapat dan syarat-syarat yang ditetapkan pun sangat sederhana. Hal tersebut adalah salah satu cara untuk mempromosikan KUR kepada calon debitur yang bertujuan oleh bank agar dapat diinformasikan secara cuma-cuma dari calon debitur 
kepada nasabah atau calon nasabah yang lainnya di PT. BRI Unit Lubuk Buaya Padang.

2) Tahap Verifikasi Berkas

Customer Service KUR mencocokkan berkas calon debitur apakah sudah lengkap atau belum yang meliputi: Kartu Tanda Penduduk (KTP) Suami-Istri, Kartu Keluarga (KK), Surat Keterangan Usaha (SKU). Setelah itu pada tahap selanjutnya melihat hasil track record calon debitur pada sistem BI yakni dengan menggunakan data SID (Sistem Informasi Nasabah), hal ini dilakukan untuk persyaratan utama program KUR pada calon debitur yang sebelumnya harus sama sekali belum pernah punya riwayat pinjaman Bank atau belum mengenal Bank (Tidak mempunyai tabungan, tidak mempunyai pinjaman dll) dikecualikan pada calon debitur yang mempunyai kredit sepeda motor.

3) Tahap Analisis Kredit atau Tahap Pemeriksaan

Menurut arahan Bank Indonesia berdasar Surat Keterangan Direksi Bank Indonesia No. 27/162/KEP/DIR Tanggal 31 Maret 1995, setiap permohonan kredit yang telah memenuhi syarat harus dianalisis secara tertulis dengan ketentuan-ketentuan :

a) Bentuk, format dan kedalaman analisis kredit ditetapkan oleh pihak bank yang disesuaikan dengan jumlah dan jenis kredit.

b) Survei ke tempat nasabah dengan melihat laporan BI Checking, menanyakan kepada tetangga kanan kiri tentang karakter calon debitur jika nasabah baru, tapi jika nasabah lama dilihat dari track record pembayaran selama ini apakah tertib membayar atauterlambat yang mengakibatkan kredit macet pada Bank.

c) Analisis kredit harus menggambarkan konsep hubungan total permohonan kredit. Analisis kredit harus dibuat secara lengkap, akurat dan obyektif yang sekurang-kurangnya meliputi: Menggambarkan semua informasi yang berkaitan dengan usaha dan data calon debitur termasuk hasil penelitian pada daftar kredit macet, Penilaian kelayakan jumlah permohonan kredit dengan kegiatan usaha yang akan dibiayai, dengan sasaran menghindari kemungkinan terjadinya hal-hal yang dapat merugikan pihak bank, dan Menyajikan penilaian yang obyektif dan tidak dipengaruhi oleh pihak-pihak yang berkepentingan dengan permohonan kredit.

Analisis kredit harus mencakup penilaian tentang prinsip 5C perkreditan dan penilaian terhadap sumber pelunasan kredit berdasarkan pada hasil usaha yang dilakukan calon debitur serta menyediakan aspek yuridis perkreditan dengan tujuan untuk melindungi bank atas resiko yang mungkin timbul.Dari hal-hal yang sudah dijelaskan, tetap tidak menutup kemungkinan bagi pihak bank untuk mengatur kebijakan kredit sesuai dengan kondisi dan kebutuhan dari PT. BRI Unit Lubuk Buaya Padang memberikan kebijakan fasilitas KUR yang disediakan adalah KUR mikro sampai dengan 20.000.000,00 (dua puluh juta rupiah). PT. BRI Unit Lubuk Buaya Padang dalam melakukan 
analisis kredit juga mempunyai kebijakan sendiri yang tentunya tetap berpedoman pada arahan Bank Indonesia. Laporan keuangan calon debitur merupakan salah satu data pokok dalam hal analisis.

Pada tahap pemeriksaan dan setelah syarat-syarat dilengkapi, Mantri KUR kantor PT. BRI Unit Lubuk Buaya Padang akan melakukan pemeriksaan serta peninjauan langsung ke lapangan tentang layak atau tidaknya calon debitur KUR diberikan pinjaman dengan menanyakan hal-hal yang berkaitan dengan permohonan KUR tersebut antara lain:a) Mencocokkan fotokopi Kartu Tanda Penduduk (KTP) sesuai dengan aslinya. b) Menanyakan hal-hal yang berhubungan dengan usaha calon debitur KUR. c) Menanyakan tentang keuntungan dari usaha calon debitur KUR.

b. Tahap Pemberian Putusan Kredit

Pada tahap ini, calon debitur akan memperoleh keputusan kredit yang berisi persetujuan akan adanya pemberian KUR sesuai permohonan yang diajukannya. Keputusan persetujuan permohonan kredit berupa mengabulkan sebagian atau seluruh permohonan kredit dari calon debitur. Pihak PT. BRI Unit Lubuk Buaya Padang akan memberitahukan kepada calon debitur untuk mengkonfirmasi kembali sekitar satu sampai dua hari (pengajuan kredit di BRI Unit tidak boleh lama sejak pendaftaran sampai dengan putusan Bank tidak lebih dari 7 hari).

Setelah itu mantra sebelum pemberian putusan kredit, Kepala Unit PT. BRI Unit Lubuk Buaya Padang wajib meneliti dan memastikan bahwa dokumen-dokumen yang berkaitan atau yang mendukung pemberian keputusan kredit masih berlaku lengkap, sah dan memiliki kekuatan hukum.

c. Tahap Pencairan Kredit atau Akad Kredit

Setelah semua persyaratan terpenuhi dan pemberian kredit telah dilengkapi dengan pelaksanaan pembuatan perjanjian kredit maka calon debitur dapat mengambil dana pinjaman yang telah dimohonkan kepada bagian Teller PT. BRI Unit Lubuk Buaya Padang. Tahap pencairan kredit meliputi:

1) Persiapan pencairan dana

Setelah Surat Keterangan Permohonan Pinjam (SKPP) diputus oleh Kepala Unit, Customer Service KUR menghubungi calon debitur untuk datang ke kantor dan setelah calon debitur datang maka Customer Service KUR mencatatnya pada register dan segera mempersiapkan pencairan dana.

Customer Service KUR memastikan bahwa yang datang harus benar-benar calon debitur beserta pasangannya yang asli dengan dibuktikan dengan meminta KTP asli. Tahap pencairan kredit meliputi:

a) Memberitahukan pada calon debitur bahwa permohonan KUR yang diajukan telah mendapat persetujuan atau putusan dan kepastian tanggal pencairan,

b) Menyiapkan Surat Pengakuan Hutang, 
c) Mengisi kwitansi pencairan dana KUR dan biaya materaiKUR.

2) Customer Service KUR membacakan pada calon debitur yang datang yang berisikan jumlah pinjaman, jangka waktu pinjaman, jumlah angsuran pinjaman beserta biayanya.

3) Penandatanganan perjanjian pencairan dana KUR

Berkas atau kelengkapan pencairan yaitu Surat Pengakuan Hutang, sebelum penandatanganan berkas pencairan KUR, Customer Service KUR harus memastikan bahwa dokumen-dokumen yang berhubungan dengan pencairan KUR telah ditandatangani oleh calon debitur sebagai bukti persetujuan debitur. Setelah itu, Customer Service KUR meminta calon debitur untuk membaca, memahami dan menandatangani Surat Pengakuan Hutang tersebut, selanjutnya diserahkan pada Kepala Unit BRI Unit Lubuk Buaya Padanguntuk diperiksa. Untuk menjaga keamanan dan melaksanakan prinsip kehati-hatian maka Customer Service KUR mencocokkan tanda tangan dengan tanda tangan debitur pada waktu pendaftaran, kemudian menyerahkan semua berkas kepada Kepala Unit PT. BRI Unit Lubuk Buaya Padang untuk melakukan pengaktifan rekening pinjaman/simpanan dan verifikasi akhir bagi melakukan fiat bayar.

4) Fiat bayar

Kepala Unit PT. BRI Unit Lubuk Buaya Padang memeriksa berkas tentang kebenaran dan kelengkapan pengisian berkas KUR untuk dicocokkan dengan syarat yang disebutkan dalam putusan kredit, setelah semua persyaratan lengkap maka Kepala Unit PT. BRI Unit Lubuk Buaya Padang memberikan tanda tangan sebagai persetujuan fiat bayar. Setelah selesai, kwitansi diserahkan pada Teller dan berkas diserahkan pada Customer Service KUR yang kemudian berguna sebagai arsip bank dan dimasukkan/diregister pada lembaga penjaminan KUR.

5) Pembayaran pencairan dana KUR

Pembayaran pencairan dana KUR kepada debitur dilakukan oleh Teller berdasarkan kwitansi pinjaman dan biaya-biaya yang diterima dari Kepala unit PT. Bank BRI Unit Lubuk Buaya Padang dengan terlebih dahulu meneliti kebenaran dan kejelasan kwitansi tersebut. Teller juga akan meminta calon debitur suami istri untuk menghadap dihadapan Teller untuk dijelaskan sekali lagi tentang para pihak yang pinjam (dibuktikan dengan dimintanya KTP oleh Teller), jumlah pinjaman, jangka waktu, angsuran, jumlah potongan dan sisa uang yang diterima oleh calon debitur.

Kebijakan dari PT. BRI Unit Lubuk Buaya, yang dapat diberikan kredit usaha rakyat ini adalah debitur yang memiliki usaha mikro, kecil, dan menengah (UMKM). PT. Bank BRI Unit Lubuk Buaya tidak turut serta menyertakan koperasi, karena sampai saat ini PT. Bank BRI Unit Lubuk Buaya Padang belum memberlakukan LinkageProgram dimana kredit terhadap UMKM dapat disalurkan melalui koperasi. 
Berdasarkan wawancara dengan pihak bank, adapun peminjaman kredit untuk plafon kredit dibawah $\mathrm{Rp} 50.000 .000$,jangka waktunya 3 tahun, dengan bunga $1.6 \%$, sedangkan untuk plafon diatas Rp 50.000.000,- jangka waktunya 5 tahun dengan bunga1\%. Untuk Kredit Usaha Rakyat (KUR) ini, Bank Rakyat Indonesia UnitLubuk Buaya hanya memberikan kredit maksimal Rp 100.000.000,.

\section{SIMPULAN}

Berdasarkan hasil penelitian yang telah dilakukan penulis pada PT. Bank Rakyat Indonesia Unit Lubuk Buaya maka dapat diambil beberapa kesimpulan sebagai berikut:

1. Kredit Usaha Rakyat (KUR) adalah kredit/ pembiayaan modal kerja dan atau investasi kepada Usaha Mikro Kecil Menengah (UMKM) di bidang usaha yang produktif dan layak namun belum bankable dengan plafon kredit sampai dengan Rp. 500.000.000,- yang sebagian dijamin oleh Perusahaan Penjamin. Sumber Dana Penyaluran KUR adalah 100\% (seratus persen) bersumber dari dana bank pelaksana yang dihimpun dari dana-dana masyarakat (tabungan, giro, dan deposito).

2. KUR dimaksudkan untuk meningkatkan akses pembiayaan bagi UMKM yang melakukan kegiatan usaha produktif dan layak namun belum bankable kepada Bank Pelaksana. KUR bertujuan untuk tercapainya percepatan pengembangan sektor riil dan pemberdayaan UMKM dalam rangka penanggulangan/pengentasan kemiskinan dan perluasan kesempatan kerja.

3. Mekanisme dalam pelaksanaan penyaluran dana Kredit Usaha Rakyat (KUR) pada PT. Bank Rakyat Indonesia Unit Lubuk Buaya. Melalui beberapa tahap diantaranya tahap pengajuan permohonan kredit, tahap pemberian putusan kredit, dan tahap pencairan kredit atau akad Kredit.

\section{UCAPAN TERIMA KASIH}

Terimakasih penulis sampaikan kepada :

1. Kedua Orang Tua yang senantiasa memberikan dukungan baik secara moril maupun materil.

2. Direktur AKBP beserta prodi AKBP yang telah memberikan kesempatan kepada penulis untuk melakukan penelitian ini.

3. Dosen Pembimbing yang telah memberikan arahan dan bimbingan hingga tugas akhir ini bisa terelesaikan.

4. Pimpinan Cabang PT. BPR-JKT Pariaman Cabang Padang yang telah mengizinkan penulis dalam memperoleh informasi beserta pengambilan data.

5. Semua Pihak yang telah memberikan dukungan dan bantuannya dalam penyelesaian tugas akhir ini 


\section{DAFTAR PUSTAKA}

Alanshari, F., \& Marlius, D. (2018). Prosedur Pemberian Kredit KPR Pada PT. Bank Tabungan Negara (Persero) TBK Cabang Pembantu Bukittinggi. https://doi.org/10.31227/osf.io/rsfhc

Amelia, L., \& Marlius, D. (2018). Pengendalian Kredit Dalam Upaya Menciptakan Bank Yang Sehat Pada PT. Bank Pembangunan Daerah Sumatera Barat Cabang Utama Padang. https://doi.org/10.31227/osf.io/kpc64

Anggraini, Dewi, dan Syahrir Hakim Nasution. 2013. "Peranan Kredit Usaha Rakyat (KUR) bagi Pengembangan UMKM di Kota Medan.” Jurnal Ekonomi Dan Keuangan 1(3): 105-16.

Prayetno, Dan Muslihudin. 2013. "Model Sistem Pendukung Keputusancpenilaian Kelayakan Pemberian Kredit.” Jurnal Sarjana Teknik Informatika 1(1): 2338-5197.

Http://Download.Portalgaruda.Org/Article.Php?Article=123621\&Val=5555 $\&$ Title=Model Sistem Pendukung Keputusan Penilaian Kelayakan Pemberian Kredit.

Darmawanto, \& Fernos, J. (2019). Prosedur Pemberian Kredit Pada Bank Nagari Cabang Sijunjung. https://doi.org/10.31227/osf.io/psqfy

Pratama, D., \& Fernos, J. (2019). Prosedur Pelaksanaan Kredit Usaha Rakyat (KUR) Pada PT. Bank Nagari Cabang Padang. https://doi.org/10.31227/osf.io/ag68j

Sari, Nurul Fitria dan Raina Linda. 2012. "Analisis Kebijakan Pemberian Kredit Dan Pengaruh Non Performing Loan Terhadap Loan To Deposit Ratio Pada Pt. Bank Rakyat Indonesia (Persero), Tbk Cabang Rantau, Aceh Tamiang. ( Periode 2007-2011).” Jurnal Ekonomi dan Keuangan, Vol.1, No.1 1(1): 88 101.

Shanjaya, A. R., \& Marlius, D. (2017). Peranan Laporan Keuangan Dalam Kebijaksanaan Pemberian Kredit Kepada Calon Nasabah Pada PT. BPR Batang Kapas. https://doi.org/10.31227/osf.io/uxmg6

Triwahyuniati, Nani. 2008. "Pelaksanaan Analisis Pemberian Kredit Di Pt Bank Haga Cabang Semarang."

Usaha kecil menengah (UKKM). 2008. "Analisis Perancangan Dan Penerapan Akuntansi Pada UKM Artagalantina." : 1-12.

Widyatama Ii, B A B, Tinjauan Pustaka, Variabel Penelitian, dan Pengertian Bank. 2011. 
Wijayadenda. 2001. "Manajemen Perbankan.” Edisi Revisi Sembilan: 25.

Zamien, Angga. 2013. "Analisis Prosedur Penyaluran Kredit Usaha Rakyat Pada

Pt. Bank Negara Indonesia (Persero) Tbk. Cabang Rengat. 